J. Dairy Sci. 92:109-116

doi:10.3168/jds.2008-1370

(c) American Dairy Science Association, 2009.

\title{
Is the temperature-humidity index the best indicator of heat stress in lactating dairy cows in a subtropical environment?
}

\author{
S. Dikmen* and P. J. Hansent ${ }^{1}$ \\ *Department of Animal Science, Faculty of Veterinary Medicine, University of Uludag, Bursa, 16059, Turkey \\ †Department of Animal Sciences, University of Florida, Gainesville 32611-0910
}

\begin{abstract}
Several temperature-humidity indexes (THI) have been used to estimate the degree of thermal stress experienced by dairy cows. The present objectives were to develop equations using meteorological variables that predicted rectal temperature of lactating cows in a subtropical environment and compare the goodness of fit of these equations to those using 8 different THI. Rectal temperature was measured between 1500 and $1700 \mathrm{~h}$ in 1,280 lactating Holstein cows in north central Florida between August and December. Meteorological data recorded in the barn where cows were located included dry bulb temperature $\left(\mathrm{T}_{\mathrm{db}}\right)$, relative humidity $(\mathrm{RH})$, dew point temperature, and wind speed. Wet bulb temperature was calculated. In the first series of analyses, regression analysis was used to model rectal temperature using the meteorological variables as well as THI. The $\mathrm{r}^{2}$ using $\mathrm{T}_{\mathrm{db}}(0.41)$ was slightly less than for models using all but one THI $\left(\mathrm{r}^{2}\right.$ between 0.42 and 0.43). The $r^{2}$ for equations using $T_{d b}$ could be improved by adding $\mathrm{RH}\left(\mathrm{r}^{2}=0.43\right)$ or $\mathrm{RH}$ and $\mathrm{RH}^{2}\left(\mathrm{r}^{2}=0.44\right)$ to the model. In the second analysis, regression analysis was performed using forward selection, backward elimination, and stepwise selection procedures with the meteorological variables. All models gave a similar goodness of fit $\left(r^{2}=0.44\right)$. An analysis of variance with rectal temperature as a class variable was performed to determine the least squares means of meteorological measurements associated with hyperthermia. $\mathrm{A} \mathrm{T}_{\mathrm{db}}$ of $29.7^{\circ} \mathrm{C}$ was associated with rectal temperature of $39^{\circ} \mathrm{C}$, and a $\mathrm{T}_{\mathrm{db}}$ of $31.4^{\circ} \mathrm{C}$ was associated with rectal temperature of $39.5^{\circ} \mathrm{C}$. In conclusion, $\mathrm{T}_{\mathrm{db}}$ is nearly as good a predictor of rectal temperatures of lactating Holsteins in a subtropical environment as THI. Estimates of values of meteorological variables associated with specific rectal temperatures should prove valuable in relating
\end{abstract}

Received May 15, 2008.

Accepted September 2, 2008.

${ }^{1}$ Corresponding author: hansen@animal.ufl.edu environmental conditions to the magnitude of hyperthermia experienced by heat-stressed cows.

Key words: temperature-humidity index, dairy cattle, rectal temperature, heat stress

\section{INTRODUCTION}

Heat stress has adverse effects on milk production and reproduction of dairy cattle (Kazdere et al., 2002; West, 2003; Hansen, 2007). As noted by Hansen (2007), the problem of heat stress is a growing one because increases in milk yield result in greater metabolic heat production and because of anticipated changes in the global climate. The magnitude of heat stress, defined here as the sum of forces external to the animal that act to displace body temperature from set point, is caused by the combined effects of dry bulb temperature $\left(\mathbf{T}_{\mathrm{db}}\right)$, humidity, solar radiation, and wind speed (WS). A variety of indices were used to estimate the degree of heat stress affecting cattle and other animals. The most common of these, the temperature-humidity index (THI), uses $T_{d b}$ and wet bulb temperature $\left(\mathbf{T}_{\mathrm{wb}}\right)$ to estimate the magnitude of heat stress (Thom, 1959). Conceptually, it is difficult to ascertain whether THI is the most appropriate measurement of heat stress in dairy cattle. There was no explanation given in the original paper for the basis of the relative weighting of $T_{d b}$ and $T_{w b}$ in the THI. Other THI were formulated empirically and often without reference to body temperatures of cattle. Nonetheless, the original THI and several variations of it have been used extensively to estimate the degree of heat stress in dairy and beef cattle (Mader et al., 2006; Bohmanova et al., 2007; Morton et al., 2007).

Despite not being formulated using cow data, THI are related to body temperatures of cattle exposed to heat stress (Ingraham et al., 1979; Buffington et al., 1981; Gaughan et al., 2008). Recently, Bohmanova et al. (2007) showed that various THI were predictive of milk yield in cows in the southeastern United States. It is not obvious that THI are better predictors of body temperature in heat-stressed cows than other measurements of environmental conditions. In addition, it is possible that regression analysis using actual data on 
environmental conditions and cow body temperature can result in development of heat stress indices that are better predictors of heat stress than THI.

There were 2 objectives of the current study. The first was to compare the effectiveness of THI models currently being used to predict heat stress in dairy cattle with other prediction equations based on environmental variables. The second was to calculate values of various meteorological variables associated with specific rectal temperatures to allow prediction of cow body temperature under various environmental conditions.

\section{MATERIALS AND METHODS}

\section{Data Collection}

The experiment was conducted with lactating Holstein cows at 3 dairies: the University of Florida Dairy Research Unit (Hague, FL; $29^{\circ} 46^{\prime} \mathrm{N}$ and $82^{\circ} 24^{\prime} \mathrm{W}$ ), Alliance Dairy (Trenton, FL; $29^{\circ} 35^{\prime} \mathrm{N}$ and $82^{\circ} 51^{\prime} \mathrm{W}$ ), and Hilltop Dairy (Trenton, FL; $29^{\circ} 35^{\prime} \mathrm{N}$ and $82^{\circ} 52^{\prime} \mathrm{W}$ ). In each farm, cows were housed in free-stall barns that were equipped with fans and sprinklers. Rectal temperature was measured in 1,280 lactating Holstein cows between August and December 2007. Rectal temperatures were recorded manually between 1500 and $1700 \mathrm{~h}$ using a digital GLA M750 thermometer (GLA Agricultural Electronics, San Luis Obispo, CA). Cows were measured while in head locks in the free-stall barn and while under shade. Various environmental measurements were taken in the barns where cows were housed. Measurements of $\mathrm{T}_{\mathrm{db}}$, relative humidity $(\mathbf{R H})$, dew point temperature $\left(\mathbf{T}_{\mathbf{d p}}\right)$, and black globe temperature $\left(\mathbf{T}_{\mathbf{b g}}\right)$ were measured at 1-min intervals between 1500 and $1700 \mathrm{~h}$ using a HOBO-U12 data logger $\left(\mathrm{T}_{\mathrm{db}}, \mathrm{RH}\right.$, and $\left.\mathrm{T}_{\mathrm{dp}}\right)$ and a HOBO Water Temp Pro V2 data logger ( $\mathrm{T}_{\mathrm{bg}}$; Onset Company, Bourne, MA) that were both located in the center of the barn at 2 $\mathrm{m}$ from the ground. Rectal temperature was matched with the measurements of $\mathrm{T}_{\mathrm{db}}, \mathrm{RH}, \mathrm{T}_{\mathrm{dp}}$, and $\mathrm{T}_{\mathrm{bg}}$ to the nearest minute at which environmental variables were recorded. Wind speed was measured at the time rectal temperature was measured using an Extech AN400 cup thermo-anemometer (Extech, Melrose, MA) positioned within arm's length of the cow being examined for rectal temperature and at a height of $\sim 2 \mathrm{~m}$ from the ground. Retrospectively, farm, parity, and DIM were recorded for each cow. In addition, milk yield data at the closest test date was available for a subset of 822 cows. For cows included in the study, milk yield averaged $24.8 \mathrm{~kg} / \mathrm{d}$ (range 4.5 to $44.0 \mathrm{~kg} / \mathrm{d}$ ), parity averaged 2.3 (range 1 to 8 ), and DIM averaged 186 (range 7 to 737$)$.

\section{Calculation of THI}

Wet bulb temperature was derived using the PsyFunc program (Linric Co., Bedford, NH) that included a package of psychrometric function programs for use with Excel 7.0 or greater (Microsoft, Redmond, WA). Values for altitude and barometric pressure for Gainesville, Florida, provided to the program were $30 \mathrm{~m}$ and $101.325 \mathrm{kPa}$, respectively.

A total of 8 THI were calculated as follows:

$$
\begin{aligned}
\mathrm{THI} 1=(1.8 & \left.\times \mathrm{T}_{\mathrm{db}}+32\right)-[(0.55-0.0055 \times \mathrm{RH}) \\
& \left.\times\left(1.8 \times \mathrm{T}_{\mathrm{db}}-26.8\right)\right]
\end{aligned}
$$

(NRC, 1971);

$$
\mathrm{THI} 2=\mathrm{T}_{\mathrm{db}}+0.36 \times \mathrm{T}_{\mathrm{dp}}+41.2
$$

(Yousef, 1985);

$$
\text { THI } 3=\left(0.35 \times \mathrm{T}_{\mathrm{db}}+0.65 \times \mathrm{T}_{\mathrm{wb}}\right) \times 1.8+32
$$

(Bianca, 1962);

$$
\text { THI } 4=\left(0.55 \times \mathrm{T}_{\mathrm{db}}+0.2 \times \mathrm{T}_{\mathrm{dp}}\right) \times 1.8+32+17.5
$$

(NRC, 1971);

$$
\text { THI5 }=\left(0.15 \times \mathrm{T}_{\mathrm{db}}+0.85 \times \mathrm{T}_{\mathrm{wb}}\right) \times 1.8+32
$$

(Bianca, 1962);

$$
\text { THI6 }=\left[0.4 \times\left(\mathrm{T}_{\mathrm{db}}+\mathrm{T}_{\mathrm{wb}}\right)\right] \times 1.8+32+15
$$

(Thom, 1959);

$$
\text { THI7 }=\left(\mathrm{T}_{\mathrm{db}}+\mathrm{T}_{\mathrm{wb}}\right) \times 0.72+40.6
$$

(NRC, 1971); and

$$
\begin{gathered}
\text { THI } 8=\left(0.8 \times \mathrm{T}_{\mathrm{db}}\right)+[(\mathrm{RH} / 100) \\
\left.\times\left(\mathrm{T}_{\mathrm{db}}-14.4\right)\right]+46.4
\end{gathered}
$$

(Mader et al., 2006).

Following the use by Bohmanova et al. (2007), temperatures were in degrees Celsius for calculation of all THI.

\section{Statistical Analysis}

Regression analysis was performed using the PROC GLM procedure of SAS (version 9.1, SAS Institute Inc., 
Cary, NC) with rectal temperature as the dependent variable. Each model included effects of parity, stage of lactation (separated into 3 stage of lactation classes: DIM $<100$, DIM between 100 and 200, and DIM $>200$ ), and farm as class variables. These terms as well as all interactions between these terms were included in all mathematical models and are referred to as the base model (BM). Regression analyses were performed using the BM with various combinations of environmental variables as continuous variables chosen a priori. These variables included $\mathrm{T}_{\mathrm{db}}, \mathrm{RH}, \mathrm{T}_{\mathrm{dp}}, \mathrm{WS}^{0.5}, \mathrm{~T}_{\mathrm{wb}}, 8$ separate THI, and the quadratic and cubic functions of these variables. The term $\mathrm{WS}^{0.5}$ was used instead of WS because of previous findings that it represents the best fit for predicting heat flow from WS (Léger and Larochelle, 2006) and because the $\mathrm{r}^{2}$ values obtained from our analyses were greater for $\mathrm{WS}^{0.5}$ than for WS. Analyses were performed with $\mathrm{T}_{\mathrm{bg}}$. The $\mathrm{T}_{\mathrm{bg}}$ were very similar to the $T_{d b}$ as were results of regression analysis with $\mathrm{T}_{\mathrm{bg}}$ and so data are not presented.

In a second series of analyses, stepwise regression analyses were performed using the PROC REG procedure of SAS. Variables in the initial model included parity, stage of lactation, farm, $\mathrm{T}_{\mathrm{db}}, \mathrm{RH}, \mathrm{T}_{\mathrm{dp}}, \mathrm{WS}^{0.5}$, and $\mathrm{T}_{\mathrm{wb}}$. Analyses were performed using forward selection, backward elimination, and stepwise selection methods. Variables with significance level $<0.15$ were retained in the model.

The PROC GLM procedure of SAS was used to estimate the mean and standard deviation of $\mathrm{T}_{\mathrm{db}}, \mathrm{T}_{\mathrm{dp}}, \mathrm{T}_{\mathrm{wb}}$, and each of the THI that were associated with rectal temperatures of $38.5,39.0,39.5,40.0,40.5$, and $41.0^{\circ} \mathrm{C}$. The mathematical model included $\mathrm{T}_{\mathrm{db}}, \mathrm{T}_{\mathrm{dp}}, \mathrm{T}_{\mathrm{wb}}$, or THI as the dependent variable and the BM and rectal temperature as independent class variables. Least squares means for each independent variable were calculated for each rectal temperature.

\section{RESULTS}

\section{Comparison of Various Environmental Variables for Modeling Rectal Temperature}

The range of meteorological variables measured in the course of the experiment and their correlation to rectal temperature is in Figure 1. The $\mathrm{r}^{2}$ obtained from regression analyses for modeling rectal temperature with various environmental variables are in Table 1 . The $r^{2}$ value for the BM only (farm, parity, stage of lactation, and interactions) was 0.24 . Initial analyses indicated that there was no significant effect of milk yield (entered as a continuous variable) on rectal temperature when added to the BM or when added to a model including farm effects, but not stage of lactation. Accordingly, milk yield was not included in further analyses.

Addition of a single meteorological variable (Table 1) increased the $r^{2}$, with the greatest improvement occurring for addition of $\mathrm{T}_{\mathrm{db}}\left(\mathrm{r}^{2}=0.41\right)$, with smaller improvements for $\mathrm{T}_{\mathrm{wb}}\left(\mathrm{r}^{2}=0.36\right)$ and $\mathrm{RH}\left(\mathrm{r}^{2}=0.29\right)$, and with little improvement when adding $\mathrm{T}_{\mathrm{dp}}$ or $\mathrm{WS}^{0.5}$. There was little or no improvement in $\mathrm{r}^{2}$ when adding the quadratic and cubic functions of any single meteorological variable to the regression equation (Table 1). In addition to models considering a single environmental variable, other models were fitted that included combinations of environmental variables. The simplest model with the greatest fit included $\mathrm{T}_{\mathrm{db}}$ and the linear and quadratic effects of $\mathrm{RH}\left(\mathrm{r}^{2}=0.44\right)$.

A second series of regression analysis was performed using forward selection, backward elimination, and stepwise selection procedures with parity, stage of lactation, farm, $\mathrm{T}_{\mathrm{db}}, \mathrm{RH}, \mathrm{T}_{\mathrm{dp}}, \mathrm{WS}^{0.5}$, and $\mathrm{T}_{\mathrm{wb}}$ as variables in the model. All selection procedures gave an $\mathrm{r}^{2}=$ 0.44 . In the forward selection model, the terms retained in the model were farm, parity, stage of lactation, $T_{d b}$, $\mathrm{RH}, \mathrm{T}_{\mathrm{dp}}$, and $\mathrm{T}_{\mathrm{wb}}$, whereas in the backward and stepwise selection models, farm, parity, stage of lactation, $\mathrm{RH}, \mathrm{T}_{\mathrm{dp}}$, and $\mathrm{T}_{\mathrm{wb}}$ remained in the model.

\section{Comparison of THI with Other Models}

Graphs illustrating the relationship between rectal temperature and THI1 and THI3 (shown as representatives of THI) are in Figure 2. The estimations of $r^{2}$ for modeling rectal temperature using THI are in Table 1. Except for THI5, the $\mathrm{r}^{2}$ values were similar for all THI and ranged between 0.42 and 0.43 . The $\mathrm{r}^{2}$ for THI5 was lower than for other THI $\left(\mathrm{r}^{2}=0.39\right)$ because of the greater importance of $\mathrm{T}_{\mathrm{wb}}$ for THI5. Addition of the quadratic and cubic functions of THI did not cause a substantial increase in $r^{2}$ (results not shown). Similarly, addition of other meteorological variables to THI models did not result in a large change in goodness of fit. The largest $r^{2}$ for the most complicated model, including the BM, THI, $\mathrm{THI}^{2}, \mathrm{~T}_{\mathrm{db}}, \mathrm{T}_{\mathrm{db}}{ }^{2}, \mathrm{RH}, \mathrm{RH}^{2}$, and $\mathrm{RH}^{3}$ was 0.45 for all THI models.

Simple correlations between meteorological values are shown in Table 2. Note that there was a correlation between $\mathrm{T}_{\mathrm{db}}$ with THI1 to THI8 $(\mathrm{r}=0.84$ for THI5 and $\mathrm{r} \geq 0.92$ for other THI). Moreover, correlations between THI were $r=0.932$ to 0.99998 . These correlations were the reason all of these variables gave a similar goodness of fit when included in regression analyses for rectal temperature. 


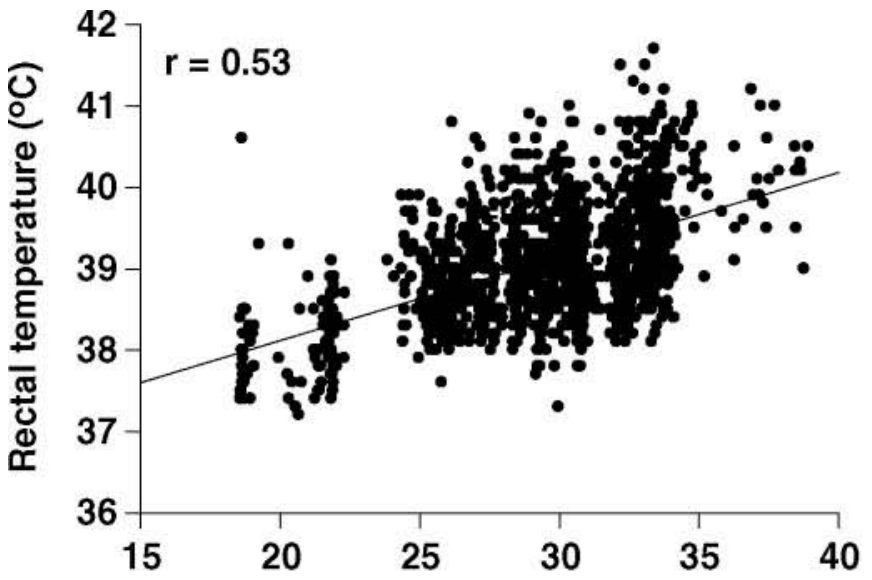

Dry bulb temperature $\left({ }^{\circ} \mathrm{C}\right)$

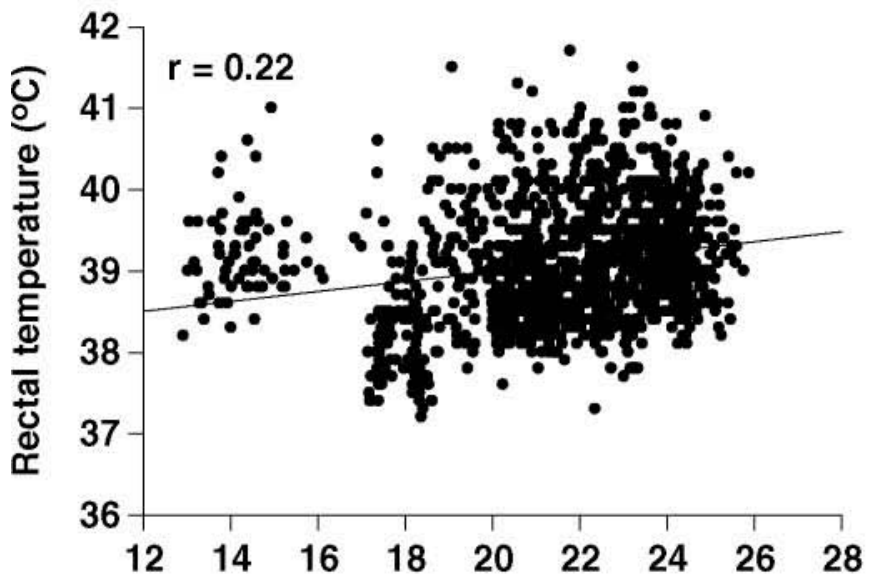

Dew point temperature $\left({ }^{\circ} \mathrm{C}\right)$
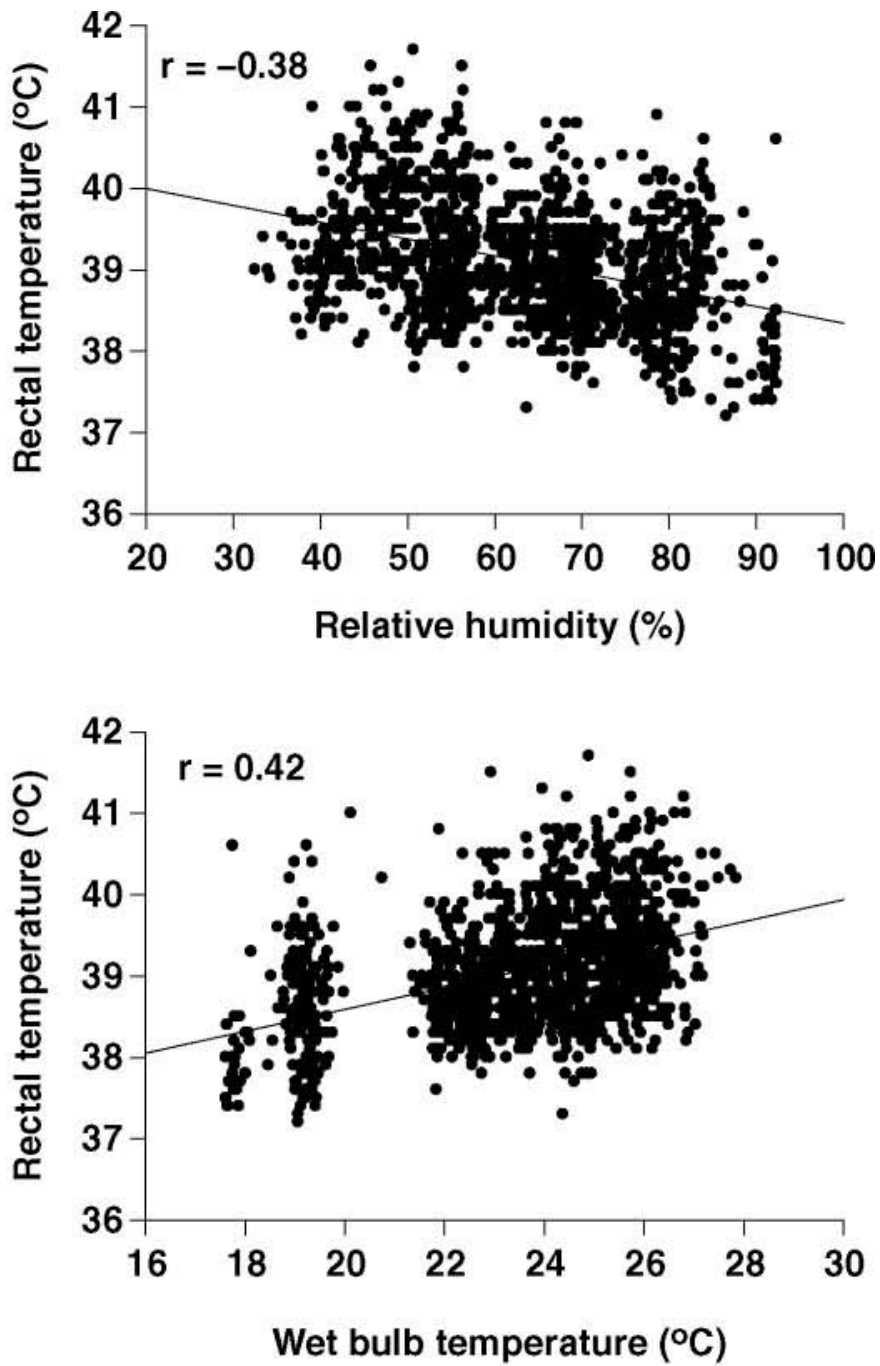

$r=-0.02$

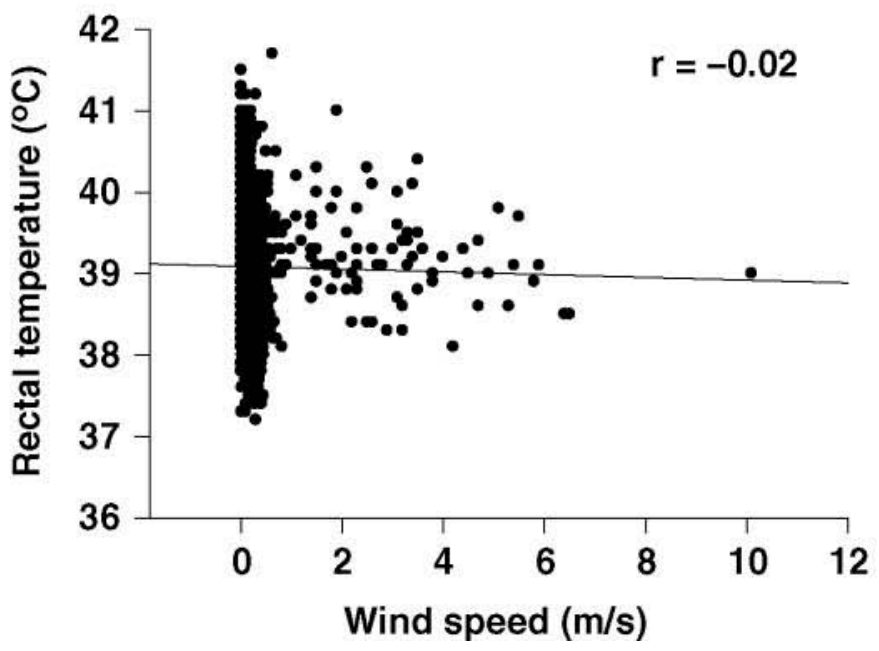

Figure 1. Relationship between rectal temperature and meteorological measurements. Points represent individual observations, lines represent simple linear regression equations, and $\mathrm{r}$ represents the simple correlation coefficient. Note that the negative correlation between rectal temperature and relative humidity reflects a correlation of $\mathrm{r}=-0.744$ between dry bulb temperature and relative humidity. 
Table 1. Coefficients of determination for predicting rectal temperature using various environmental variables

\begin{tabular}{|c|c|}
\hline Model $^{1}$ & $\mathrm{r}^{2}$ \\
\hline Base model (BM) & 0.24 \\
\hline $\mathrm{BM}+\mathrm{T}_{\mathrm{db}}$ & 0.41 \\
\hline $\mathrm{BM}+\mathrm{T}_{\mathrm{db}}+\mathrm{T}_{\mathrm{db}}^{2}$ & 0.41 \\
\hline $\mathrm{BM}+\mathrm{T}_{\mathrm{db}}+\mathrm{T}_{\mathrm{db}}{ }^{2}+\mathrm{T}_{\mathrm{db}}{ }^{3}$ & 0.41 \\
\hline $\mathrm{BM}+\mathrm{RH}$ & 0.29 \\
\hline $\mathrm{BM}+\mathrm{RH}+\mathrm{RH}^{2}$ & 0.29 \\
\hline $\mathrm{BM}+\mathrm{RH}+\mathrm{RH}^{2}+\mathrm{RH}^{3}$ & 0.32 \\
\hline $\mathrm{BM}+\mathrm{T}_{\mathrm{dp}}$ & 0.27 \\
\hline $\mathrm{BM}+\mathrm{T}_{\mathrm{dp}}+\mathrm{T}_{\mathrm{dp}}^{2}$ & 0.28 \\
\hline $\mathrm{BM}+\mathrm{T}_{\mathrm{dp}}+\mathrm{T}_{\mathrm{dp}}{ }^{2}+\mathrm{T}_{\mathrm{dp}}{ }^{3}$ & 0.28 \\
\hline $\mathrm{BM}+\mathrm{WS}^{0.5}$ & 0.25 \\
\hline $\mathrm{BM}+\mathrm{WS}^{0.5}+\left(\mathrm{WS}^{0.5}\right)^{2}$ & 0.25 \\
\hline $\mathrm{BM}+\mathrm{WS}^{0.5}+\left(\mathrm{WS}^{0.5}\right)^{2}+\left(\mathrm{WS}^{0.5}\right)^{3}$ & 0.26 \\
\hline $\mathrm{BM}+\mathrm{T}_{\mathrm{wb}}$ & 0.36 \\
\hline $\mathrm{BM}+\mathrm{T}_{\mathrm{wb}}+\mathrm{T}_{\mathrm{wb}}^{2}$ & 0.37 \\
\hline $\mathrm{BM}+\mathrm{T}_{\mathrm{wb}}+\mathrm{T}_{\mathrm{wb}}{ }^{2}+\mathrm{T}_{\mathrm{wb}}{ }^{3}$ & 0.38 \\
\hline $\mathrm{BM}+\mathrm{T}_{\mathrm{db}}+\mathrm{RH}+\mathrm{T}_{\mathrm{wb}}$ & 0.43 \\
\hline $\mathrm{BM}+\mathrm{T}_{\mathrm{db}}+\mathrm{RH}+\mathrm{RH}^{2}+\mathrm{T}_{\mathrm{wb}}$ & 0.44 \\
\hline $\mathrm{BM}+\mathrm{T}_{\mathrm{db}}+\mathrm{RH}$ & 0.43 \\
\hline $\mathrm{BM}+\mathrm{T}_{\mathrm{db}}+\mathrm{RH}+\mathrm{RH}^{2}$ & 0.44 \\
\hline $\mathrm{BM}+\mathrm{T}_{\mathrm{db}}+\mathrm{RH}+\mathrm{RH}^{2}+\mathrm{RH}^{3}$ & 0.44 \\
\hline $\mathrm{BM}+\mathrm{T}_{\mathrm{db}}+\mathrm{T}_{\mathrm{dp}}+\mathrm{T}_{\mathrm{dp}}{ }^{2}+\mathrm{T}_{\mathrm{dp}}{ }^{3}$ & 0.43 \\
\hline $\mathrm{BM}+\mathrm{T}_{\mathrm{db}}+\mathrm{T}_{\mathrm{dp}}+\mathrm{T}_{\mathrm{dp}}{ }^{2}+\mathrm{T}_{\mathrm{dp}}{ }^{3}+\mathrm{WS}^{0.5}+\left(\mathrm{WS}^{0.5}\right)^{2}+\left(\mathrm{WS}^{0.5}\right)^{3}$ & 0.43 \\
\hline $\mathrm{BM}+\mathrm{T}_{\mathrm{db}}+\mathrm{T}_{\mathrm{db}}+\mathrm{RH}$ & 0.43 \\
\hline $\mathrm{BM}+\mathrm{T}_{\mathrm{db}}+\mathrm{T}_{\mathrm{db}}{ }^{2}+\mathrm{T}_{\mathrm{dp}}$ & 0.43 \\
\hline $\mathrm{BM}+\mathrm{T}_{\mathrm{db}}+\mathrm{T}_{\mathrm{db}}{ }^{2}+\mathrm{WS}^{0.5}$ & 0.41 \\
\hline $\mathrm{BM}+\mathrm{T}_{\mathrm{db}}+\mathrm{RH}+\mathrm{T}_{\mathrm{dp}}+\mathrm{T}_{\mathrm{wb}}$ & 0.44 \\
\hline BM + THI1 & 0.43 \\
\hline $\mathrm{BM}+\mathrm{THI} 2$ & 0.42 \\
\hline $\mathrm{BM}+\mathrm{THI} 3$ & 0.42 \\
\hline $\mathrm{BM}+\mathrm{THI} 4$ & 0.43 \\
\hline $\mathrm{BM}+\mathrm{THI} 5$ & 0.39 \\
\hline $\mathrm{BM}+\mathrm{THI} 6$ & 0.43 \\
\hline $\mathrm{BM}+\mathrm{THI} 7$ & 0.43 \\
\hline $\mathrm{BM}+\mathrm{THI} 8$ & 0.43 \\
\hline
\end{tabular}

${ }^{1}$ Base model includes adjustments of rectal temperature for parity, stage of lactation, farm, and all interactions between parity, stage of lactation, and farm. $\mathrm{T}_{\mathrm{db}}=$ dry bulb temperature; $\mathrm{RH}=$ relative humidity; $\mathrm{T}_{\mathrm{dp}}=$ dew point temperature; $\mathrm{T}_{\mathrm{wb}}=$ wet-bulb temperature; $\mathrm{WS}=$ wind speed; $\mathrm{THI}=$ temperature-humidity index.

\section{Predicted Values of Environmental Variables That Cause Hyperthermia}

An ANOVA was used to estimate the least squares means and standard errors of $\mathrm{T}_{\mathrm{db}}, \mathrm{T}_{\mathrm{wb}}$, and THI associated with average rectal temperatures of 38.5, 39.0, $39.5,40.0,40.5$, and $41.0^{\circ} \mathrm{C}$. Results are in Table 3 .

\section{DISCUSSION}

The ability of homeotherms to successfully maintain a constant body temperature can be compromised when environmental conditions limit the loss of metabolic heat or contribute to the heat load of the animal (i.e., when surrounding temperature is greater than surface temperature or heat is gained from other objects by radiation). These environmental conditions include not only $\mathrm{T}_{\mathrm{db}}$, which affects sensible heat loss via conduction and convection, but also humidity, because it affects the amount of latent heat loss; wind speed, which affects rate of sensible and latent heat loss; and radiation. Estimates of the degree of heat stress affecting animal regulation of body temperature were made by developing mathematical formulae that combine one or more meteorological variables. Here we show, that for lactating dairy cows in a subtropical environment, the most commonly used indices, collectively termed THI, explain much of the variation between cows in rectal temperature. At a practical level, the predictive value of THI is only slightly better than $\mathrm{T}_{\mathrm{db}}$ alone, because there were very high correlations between $\mathrm{T}_{\mathrm{db}}$ and THI1 to THI8. Thus, little is to be gained in terms of evaluating an environment by using THI instead of $T_{\mathrm{db}}$.

Data for the current study were collected in a subtropical environment in which high humidity was a prevailing characteristic (Figure 1). It is possible that the effectiveness of various heat stress indices will vary 

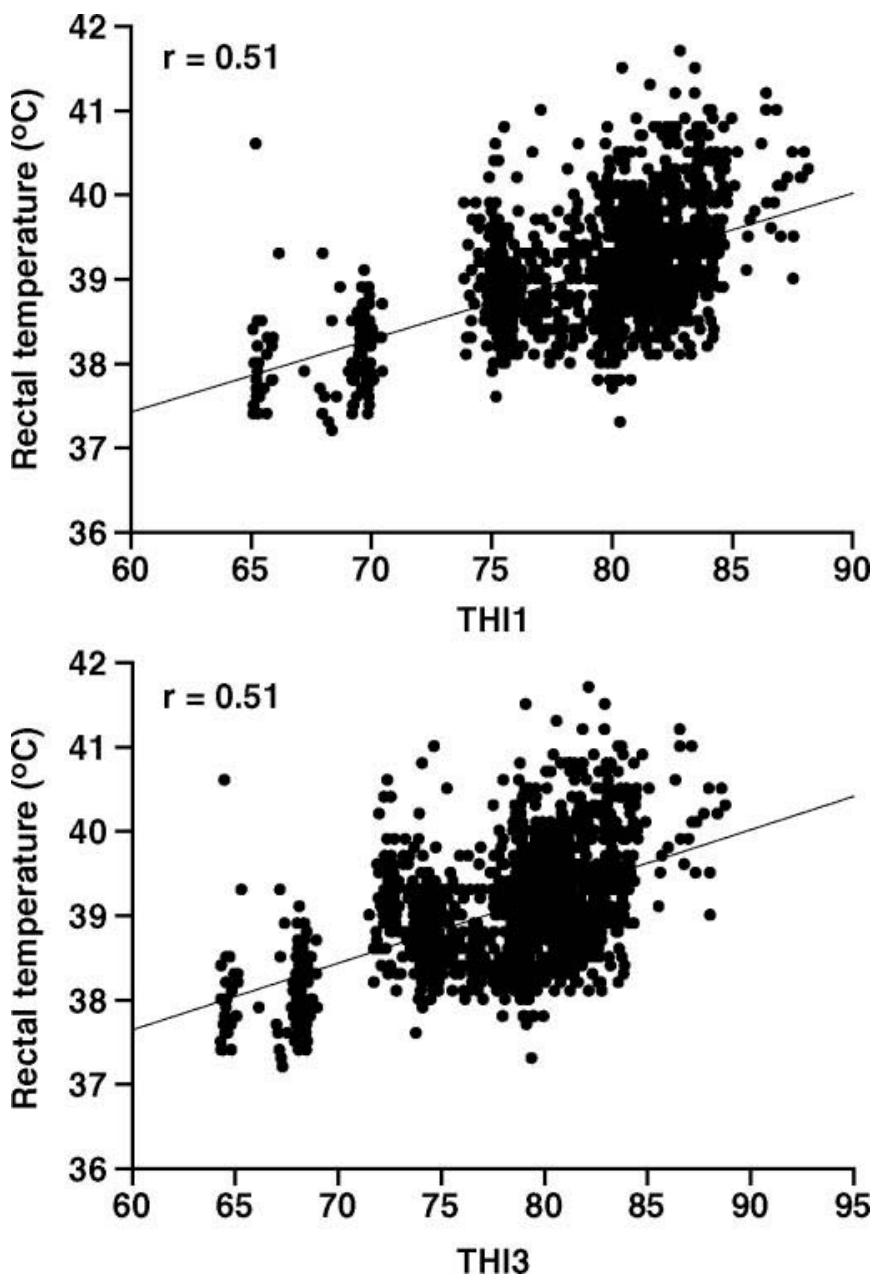

Figure 2. Relationship between rectal temperature and temperature humidity index (THI)1 and THI3. Points represent individual observations, lines represent simple linear regression equations, and $r$ represents the simple correlation coefficient.

with climate. Using milk yield data as an end point, Bohmanova et al. (2007) demonstrated that THI that weighted humidity more heavily were better for cattle in Georgia, where humidity is high, whereas THI that weighted humidity to a lesser degree were better for cattle in Arizona, where humidity is low. Wind speed was not an important determinant of rectal temperature in the current study, although forced ventilation decreased body temperature in dairy cows (Berman et al., 1985). Air velocity was low $(<1 \mathrm{~m} / \mathrm{s})$ in most instances, and it is possible that the lack of relationship between air velocity and rectal temperature reflected a paucity of cows exposed to air velocities sufficient to alter thermal balance. Black globe temperature was not a valuable meteorological trait in the current study, because the value was very similar to $T_{d b}$ (data not shown). Similar results were seen in other environments where cows received extensive shade (Hansen, 1990). In environments characterized by intense solar radiation, it is likely that use of $\mathrm{T}_{\mathrm{bg}}$ will improve ability of heat stress indices to predict rectal temperature (Buffington et al., 1981).

It was expected that regulation of body temperature during hyperthermia would be decreased as milk yield increased because of the metabolic heat output associated with lactation. This was demonstrated experimentally in dairy cows in Israel (Berman et al., 1985) and theoretically using mathematical models of heat balance in dairy cows (Berman, 2005). In addition, the summer depression in fertility in dairy cows was more pronounced for cows with greater milk yield (Al-Katanani et al., 1999). Given these observations, it was a surprise that there was no significant relationship between milk yield and rectal temperature. Perhaps, the failure to find a relationship was because cows that have greater capacity for regulation of body temperature, through genetic inheritance (Ravagnolo and Misztal, 2000) or otherwise, may have greater milk yield as a result. Alternatively, because milk yield was not measured on the day of rectal temperature measurement, this may have obscured an effect of milk yield.

Temperature humidity indices are often placed into classes to indicate the degree of heat stress (Armstrong, 1994; Mader et al., 2006). The terms used to describe these classes and the ranges of THI used to define each class are arbitrary. In the current study, average meteorological variables were determined associated with specific rectal temperatures. This approach has the advantage over previous classifications in that the specific rectal temperature likely experienced by animals can be estimated at various environmental conditions. This information can be combined with experimental data indicating at which body temperature deviations in milk yield and reproduction occur to more accurately assess thermal environment and its effect on animal health and production. For example, it was estimated that conception rate declined by $12 \%$ for each $0.5^{\circ} \mathrm{C}$ increase in uterine temperature above $38.6^{\circ} \mathrm{C}$ (Gwazdauskas et al., 1973). Accordingly, decreased fertility could be expected at environmental conditions causing a rectal temperature of $39^{\circ} \mathrm{C}$. Data in Table 1 indicate such a rectal temperature would occur at a $\mathrm{T}_{\mathrm{db}}$ of $29.7^{\circ} \mathrm{C}$.

The $\mathrm{T}_{\mathrm{db}}$ at which rectal temperature was $38.5^{\circ} \mathrm{C}$ was $28.4^{\circ} \mathrm{C}$. This value of $28.4^{\circ} \mathrm{C}$ represents the upper critical temperature, because hyperthermia would be expected at $T_{d b}$ above this value. Our estimate of upper critical temperature is greater than the value of upper critical temperature obtained by Berman et al. (1985) for lactating dairy cows in Israel $\left(25\right.$ to $\left.26^{\circ} \mathrm{C}\right)$. Similarly, our estimate of the upper critical THI (the THI at which rectal temperature is $38.5^{\circ} \mathrm{C}$ ) is greater than 
Table 2. Simple correlations between environmental variables ${ }^{1,2}$

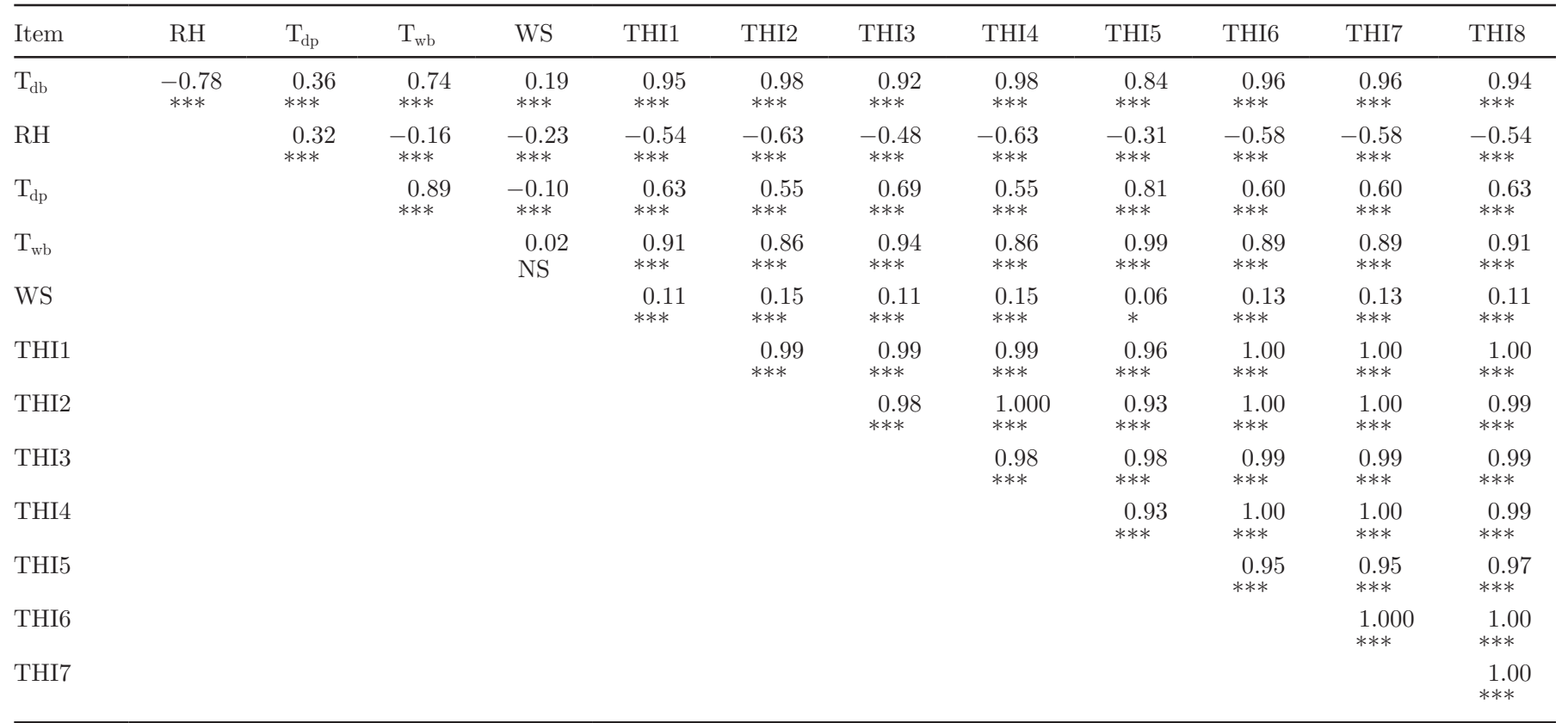

${ }^{1} \mathrm{~T}_{\mathrm{db}}=$ dry bulb temperature; $\mathrm{T}_{\mathrm{dp}}=$ dew point temperature; $\mathrm{T}_{\mathrm{wb}}=$ wet bulb temperature; WS $=$ wind speed; THI $=$ temperature-humidity index.

${ }^{2}$ Correlations listed as 1.000 were actually slightly lower than 1 .

${ }^{*} P<0.05 ;{ }^{* * *} P<0.001$

the estimates by Bohmanova et al. (2007) for threshold THI above which milk yield declined. For example, the upper critical THI using THI 1 was $78.2^{\circ} \mathrm{C}$ in the current study compared with $72^{\circ} \mathrm{C}$ for cows in Georgia and $74^{\circ} \mathrm{C}$ for cows in Arizona (Bohmanova et al., 2007). Perhaps, cows in the current study were more adapted to heat stress or other features of their housing decreased the magnitude of heat stress. In addition, cows were in free-stall barns with fans and sprinklers, and the presence of these devices may have resulted in an increase in upper critical temperature.

In conclusion, $\mathrm{T}_{\mathrm{db}}$ is nearly as good a predictor of rectal temperatures of lactating Holsteins in a subtropical environment as THI. Estimates of values of meteorological variables associated with specific rectal temperatures should prove valuable in relating environmental conditions to the magnitude of hyperthermia experienced by heat-stressed cows.

Table 3. Least squares means $( \pm \mathrm{SE})$ for environmental variables at various rectal temperatures ${ }^{1}$

\begin{tabular}{|c|c|c|c|c|c|c|c|c|c|c|c|c|}
\hline $\begin{array}{l}\text { Rectal } \\
\text { temperature } \\
\left({ }^{\circ} \mathrm{C}\right)\end{array}$ & \multicolumn{2}{|c|}{$\mathrm{T}_{\mathrm{db}}\left({ }^{\circ} \mathrm{C}\right)$} & \multicolumn{2}{|c|}{$\mathrm{T}_{\mathrm{dp}}\left({ }^{\circ} \mathrm{C}\right)$} & \multicolumn{2}{|c|}{$\mathrm{T}_{\mathrm{wb}}\left({ }^{\circ} \mathrm{C}\right)$} & \multicolumn{2}{|c|}{ THI1 } & \multicolumn{2}{|c|}{ THI2 } & \multicolumn{2}{|c|}{ THI3 } \\
\hline 38.5 & 28.4 & 0.36 & 21.2 & 0.32 & 23.2 & 0.21 & 78.2 & 0.37 & 77.3 & 0.39 & 77.1 & 0.41 \\
\hline 39.5 & 31.4 & 0.36 & 22.3 & 0.31 & 24.7 & 0.21 & 81.5 & 0.36 & 80.6 & 0.38 & 80.7 & 0.41 \\
\hline 40 & 32.2 & 0.48 & 22.5 & 0.42 & 25.0 & 0.29 & 82.3 & 0.49 & 81.5 & 0.51 & 81.6 & 0.55 \\
\hline 40.5 & 34.1 & 0.64 & 22.2 & 0.56 & 25.3 & 0.38 & 83.6 & 0.65 & 82.3 & 0.68 & 83.1 & 0.73 \\
\hline 38.5 & 85.3 & 0.38 & 75.2 & 0.39 & 84.2 & 0.36 & 77.8 & 0.36 & 78.1 & 0.36 & & \\
\hline 39 & 86.6 & 0.33 & 76.3 & 0.34 & 85.5 & 0.31 & 79.1 & 0.31 & 79.5 & 0.31 & & \\
\hline 39.5 & 88.6 & 0.38 & 78.3 & 0.38 & 87.4 & 0.36 & 81.0 & 0.36 & 81.4 & 0.36 & & \\
\hline 40 & 89.5 & 0.51 & 79.1 & 0.51 & 88.2 & 0.48 & 81.8 & 0.48 & 82.2 & 0.48 & & \\
\hline 40.5 & 91.3 & 0.67 & 80.0 & 0.68 & 89.8 & 0.64 & 83.4 & 0.64 & 83.5 & 0.64 & & \\
\hline 41 & 92.3 & 1.23 & 80.7 & 1.26 & 90.8 & 1.17 & 84.4 & 1.17 & 84.4 & 1.17 & & \\
\hline
\end{tabular}

${ }^{1} \mathrm{~T}_{\mathrm{db}}=$ dry bulb temperature; $\mathrm{T}_{\mathrm{dp}}=$ dew point temperature; $\mathrm{T}_{\mathrm{wb}}=$ wet bulb temperature; $\mathrm{THI}=$ temperature-humidity index. 


\section{ACKNOWLEDGMENTS}

Serdal Dikmen was supported by a grant from TUBITAK-BIDEB, Ankara, Turkey. We thank the following individuals for providing access to cows and cow records: Eric Diepersloot of the University of Florida Dairy Research Unit, Ron St. John and the employees of Alliance Dairy, and Pam Bliss and the employees of Hilltop Dairy. Thanks are expressed to Meghan M. Brennan of the Department of Statistics, University of Florida, for providing statistical advice.

\section{REFERENCES}

Al-Katanani, Y. M., D. W. Webb, and P. J. Hansen. 1999. Factors affecting seasonal variation in 90-day nonreturn rate to first service in lactating Holstein cows in a hot climate. J. Dairy Sci. 82:2611-2616.

Armstrong, D. V. 1994. Heat stress interaction with shade and cooling. J. Dairy Sci. 77:2044-2050.

Berman, A. 2005. Estimates of heat stress relief needs for Holstein dairy cows. J. Anim. Sci. 83:1377-1384.

Berman, A., Y. Folman, M. Kaim, M. Mamen, Z. Herz, D. Wolfenson, A. Arieli, and Y. Graber. 1985. Upper critical temperatures and forced ventilation effects for high-yielding dairy cows in a subtropical climate. J. Dairy Sci. 68:1488-1495.

Bianca, W. 1962. Relative importance of dry- and wet-bulb temperatures in causing heat stress in cattle. Nature 195:251-252.

Bohmanova, J., I. Misztal, and J. B. Cole. 2007. Temperature-humidity indices as indicators of milk production losses due to heat stress. J. Dairy Sci. 90:1947-1956.

Buffington, D. E., A. Collazo-Arocho, G. H. Canton, D. Pitt, W W. Thatcher, and R. J. Collier. 1981. Black globe-humidity index (BGHI) as comfort equation for dairy cows. Trans. ASAE 24:711-714.
Gaughan, J. B., T. L. Mader, S. M. Holt, and A. Lisle. 2008. A new heat load index for feedlot cattle. J. Anim. Sci. 86:226-234.

Gwazdauskas, F. C., W. W. Thatcher, and C. J. Wilcox. 1973. Physiological, environmental, and hormonal factors at insemination which may affect conception. J. Dairy Sci. 56:873-877.

Hansen, P. J. 1990. Effects of coat colour on physiological and milk production responses to solar radiation in Holsteins. Vet. Rec. 127:333-334.

Hansen, P. J. 2007. Exploitation of genetic and physiological determinants of embryonic resistance to elevated temperature to improve embryonic survival in dairy cattle during heat stress. Theriogenology 68S:S242-S249.

Ingraham, R. H., R. W. Stanley, and W. C. Wagner. 1979. Seasonal effects of tropical climate on shaded and nonshaded cows as measured by rectal temperature, adrenal cortex hormones, thyroid hormone, and milk production. Am. J. Vet. Res. 40:1792-1797.

Kazdere, C. T., M. R. Murphy, N. Silanikove, and E. Maltz. 2002 Heat stress in lactating dairy cows: A review. Livest. Prod. Sci. 77:59-91.

Léger, J., and J. Larochelle. 2006. On the importance of radiative heat exchange during nocturnal flight in birds. J. Exp. Biol. 209:103114.

Mader, T. L., M. S. Davis, and T. Brown-Brandl. 2006. Environmental factors influencing heat stress in feedlot cattle. J. Anim. Sci 84:712-719.

Morton, J. M., W. P. Tranter, D. G. Mayer, and N. N. Jonsson. 2007. Effects of environmental heat on conception rates in lactating dairy cows: Critical periods of exposure. J. Dairy Sci. 90:2271-2278.

NRC. 1971. A Guide to Environmental Research on Animals. Natl Acad. Sci., Washington, DC.

Ravagnolo, O., and I. Misztal. 2000. Genetic component of heat stress in dairy cattle, parameter estimation. J. Dairy Sci. 83:21262130

Thom, E. C. 1959. The discomfort index. Weatherwise 12:57-59.

West, J. W. 2003. Effects of heat-stress on production in dairy cattle. J. Dairy Sci. 86:2131-2144

Yousef, M. K. 1985. Stress Physiology in Livestock. CRC Press, Boca Raton, FL. 